\title{
A FRONTEIRA COMO ESPAÇO DE TRABALHO: O MERCADO DE TRABALHO NO CONTEXTO DAS REGIÕES DE FRONTEIRA DE BRASIL E BOLÍVIA
}

\author{
Pedro Aguiar \\ UFRJ - Universidade Federal do Rio de Janeiro
}

\section{Resumo}

\begin{abstract}
Nos últimos anos os fluxos de imigrantes entre a Bolívia e o Brasil cresceram, isso fez com que houvesse mudanças nas dinâmicas do mercado de trabalho dos países. Essas mudanças impactariam de forma diferenciada dentro da Zona de Fronteira entre os países, já que existiria uma tendência para que esse fluxo estivesse muito presente na região. Sendo assim, essa pesquisa teve como objetivo analisar a dinâmica do mercado de trabalho na Zona de Fronteira entre Brasil e Bolívia, observando a migração da população boliviana e as atividades exercidas por esses migrantes. Para isso foram coletados dados relativos a entrada e registros dos migrantes, setores de atividade de trabaIho e tipo de trabalho formal e informal dos bolivianos no Brasil.
\end{abstract}

Palavras-chave: Zona de Fronteira; Mercado de trabaIho; Migração.
Resumen

En los últimos años los flujos de inmigrantes entre Bolivia y Brasil crecieron, eso hizo que hubiese cambios en las dinámicas del mercado de trabajo de los países. Estos cambios impactaran de forma diferenciada dentro de la Zona de Frontera entre los países, ya que existiría una tendencia a que ese flujo estuviera muy presente en la región. Siendo así, esta investigación tuvo como objetivo analizar la dinámica del mercado de trabajo en la Zona de Frontera entre Brasil y Bolivia, observando la migración de la población boliviana y las actividades ejercidas por esos migrantes. Para eso fueron recolectados datos relativos a la entrada y registros de los migrantes, sectores de actividad de trabajo y tipo de trabajo formal e informal de los bolivianos en Brasil.

Palabras-clave: Zona de Frontera; Mercado de trabajo; Migración.

\section{Introdução}

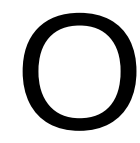

fluxo de trabalhadores entre países tem sido um fenômeno cada vez mais recorrente nos últimos anos, facilitado pelos avanços tecnológicos e instrumentos políticos apresentados pela globalização. Porém, isso não significa que estas facilidades alcancem todos os migrantes, existindo ainda diversas barreiras para determinados grupos ao realizar a imigração, sejam estas barreiras legais, sociais, econômicas, culturais ou até mesmo físicas.

Outro elemento que influencia na mobilidade e nesse caso para aqueles que buscam o trabalho é que a mobilidade geográfica do capital se tornou ainda muito mais fluída em comparação com a do trabalho e o trabalhador, o que garante ao primeiro um maior poder de barganha. 
Assim, a ameaça constante de transferência de atividades produtivas é um importante instrumento na mesa de negociação de salários, benefícios e contratos com empregados.

Em situações específicas, onde não é possível realocar as atividades, ainda existe uma busca por trabalhadores de baixo custo. Em muitas dessas situações é comum recrutar o trabalho migrante, por ele estar em uma situação de maior vulnerabilidade em busca de trabalho para se estabilizar em sua nova residência.

Mesmo diante da possibilidade de um cenário de baixos salários e alta vulnerabilidade, muitos foram aqueles que se deslocaram, seja motivado por elementos econômicos, conectados por meio de redes sociais de imigrantes ou então buscando por outras oportunidades de trabalho. Além disso, o imigrante ainda sonha com a possibilidade de ascensão social e econômica em um outro país, mesmo que muitas vezes essa ascensão seja limitada pelo fato de ele ser um imigrante, e os fatores políticos e sociais criem barreiras para isso.

Mesmo que por outras motivações, o trabalho ainda surge como um elemento quase intrínseco à imigração, devido à sua necessidade para a estabilidade. A mobilidade desses trabaIhadores terá um peso dentro do mercado de trabalho, pois ele deve absorver esses novos imigrantes, seja pelo setor formal, como pelo informal.

Dentro de uma região como a zona de fronteira esse fenômeno terá elementos que vão diferenciá-lo devido à proximidade entre dois espaços de grandes diferenças culturais, econômicas e principalmente legislativas. A partir desse contraste entre os dois lados que se pode ter uma dinâmica para um mercado de trabalho na zona de fronteira, onde existe um lado que terá uma maior oferta de empregos e outro com uma pressão demográfica e busca por melhores condições trabalhistas (mais direitos) e de salário (HOUSE,1980).

Para analisar isso, essa pesquisa pretende explorar tal situação no contexto particular da fronteira do Brasil com a Bolívia, países que a partir dos anos 1990 aumentaram suas relações econômicas e políticas, estabelecendo uma série de acordos bilaterais para as atividades laborais realizadas no âmbito dos dois países, sendo exercidas por migrantes ou por trabalhadores pendulares. No caso do Brasil o que se tem observado nos últimos anos é um interesse geopolítico em uma possível integração do mercado sul-americano e uma conectividade com os países vizinhos, como parte de uma estratégia para a expansão do seu mercado. Essas mudanças políticas podem ser um dos elementos que contribuíram para a intensificação da migração entre os países. Em relação à Bolívia, existe já um histórico de migração da sua população, durante esse mesmo período de intensificação das relações políticas, houve um crescimento da emigração, o que pode ser decorrente dos problemas socioeconômicos locais e a situação que enfrentava a política local, e tendo sido muitos desses emigrantes atraídos para o Brasil em busca de um panorama diferente (SOUCHAUD, 2010; MERÇON, 2015).

Levantamentos feitos recentemente, mostraram que o deslocamento dos bolivianos muitas vezes se deu diretamente para maiores centros econômicos do país, principalmente São Paulo (SP) (AMARAL, 2017). Entretanto, a região de fronteira se mostrou ser mais que um espaço de passagem para esses trabalhadores. Muitos dos imigrantes se estabelecem dentro das cidades de fronteira, bem como existem aqueles que realizam mobilidade constante, trabalhando de um lado e morando do outro lado da fronteira. Seria, portanto a fronteira uma região na qual esses trabalhadores possam se estabelecer também? E que tipo de atividades seriam mais realizadas 
dentro desses espaços e talvez favorecidas por essa condição geográfica diferenciada?

A partir desses questionamentos se estabeleceu como objetivo principal buscar analisar as dinâmicas e fenômenos locais no mercado de trabalho dentro das regiões de fronteira de Brasil e Bolívia. Como objetivos específicos vai se buscar (i) verificar a mobilidade e permanência de trabalhadores da Bolívia para o Brasil; (ii) e levantar os tipos de atividades presentes em cada uma das regiões, realizadas por locais e imigrantes.

Para atender a esses objetivos foi traçado como método operacional a coleta e análise de dados secundários de diversas fontes. Para um levantamento da emigração de bolivianos para o Brasil foi feito um levantamento dos Censos Demográficos de 2001 e 2012 do Instituto Nacional de Estadística (INE) da Bolívia. Já em relação a entrada dos imigrantes no Brasil se utilizou os dados do Sistema Nacional de Cadastro e Registro de Estrangeiros (SINCRE) dos anos 2000 a 2015, feitos pela polícia federal, com os dados do ano e estado de entrada dos imigrantes, bem como o atual local de residência e a sua profissão atual. Para identificar as principais atividades de trabalho realizadas dentro da zona de fronteira e o trabalho dos imigrantes foram utilizados dados do Relatório Anual de Informações Sociais (RAIS), do Ministério do Trabalho e Emprego, para o período também de 2000 a 2015. Por fim, para tentar cobrir alguns fenômenos invisibilizados, como o mercado informal e aqueles bolivianos não cadastrados coletou-se também dados do Censo Demográfico de 2010 do Instituto Brasileiro de Geografia e Estatística (IBGE).

O recorte espacial a ser analisado, como já mencionado, é o da Zona de Fronteira entre Brasil e Bolívia. Para determinar a área incluída nessa região foi utilizado como critério o que cada país estipulou como a sua região de fronteira. Na Bolívia segundo o artigo 25 da constituição de 1994, existe até 50 quilômetros, a partir do limite político, uma região de fronteira, na qual estrangeiros não podem adquirir nem possuir nenhum tipo de solo. Já no Brasil o artigo 20 da constituição de 1988 reforça a importância da Faixa de Fronteira, fundamental para a defesa do território nacional, seguindo as normas da lei 6.634 de 1979, estipulando que a região de fronteira seria composta pelos municípios inseridos integrais ou parcialmente na faixa de $150 \mathrm{~km}$ a partir do limite político internacional.

Já para o recorte temporal para ser investigado, o período de 2000 a 2015 aparece com maior relevância, por abranger justamente um recorte recente do fenômeno a ser analisado e o período de crescimento das relações entre os dois países, bem como o intenso crescimento da imigração boliviana para o Brasil. Outro fator importante para a análise que está presente dentro desse recorte é a mudança de perspectiva geopolítica da América do Sul, a partir de uma visão integradora, que surge nos anos 1990, como a criação dos blocos econômicos, como o MERCOSUL, que tem o Brasil como um dos fundadores e a Bolívia como associada em processo de adesão. Essa perspectiva de integração se intensifica durante os anos 2000 com a adoção de políticas visando expandir o papel do Brasil como potência regional na América do Sul.

\section{Emigração de trabalhadores bolivianos para o Brasil}

Um dos fenômenos que vai ter efeitos importantes dentro do mercado de trabalho fronteiriço é a migração da população, sendo grande parte desses trabalhadores estabelecendo relações para 
os dois lados. A emigração de bolivianos será relevante para esse mercado, por apresentar uma mão de obra alternativa, com diferentes especializações, mas que também acaba explorada por conta da sua situação de marginalização. A emigração dos bolivianos se deu de maneira mais intensa a partir dos anos 1990, decorrente das diversas crises políticas e econômicas no país. Segundo Bandeira (2002), uma das hipóteses para explicar esse fenômeno é que a partir de 1985 as escolhas políticas do país, como a adoção do sistema de livre mercado e um modelo neoliberal de governar, resultou em uma deterioração das condições de vida dos trabalhadores, principalmente os do campo, com $80 \%$ deles reduzidos à condição de miséria.

A conjuntura do momento apontava para mudanças nas formas de trocas entre países. Com o fim da Guerra Fria o que procede é um contexto de globalização e busca por integração entre os países, com a criação de blocos econômicos, maior abertura para os fluxos econômicos e populacionais. Na América do Sul o MERCOSUL surge em 1991, como resposta à busca por essa integração regional entre os países e para maior facilidade de migração entre os países.

Apesar de inicialmente a Bolívia não ser um país membro ou associado do bloco, essa se encontra próxima aos demais países fundadores e membros, o que indicava uma perspectiva de expandir seu papel no contexto sul-americano. Este fato aliado à queda brusca na condição de vida do povo boliviano fez com que muitos trabalhadores fossem buscar alternativas de trabalho em outros países. O destino de muitos deles foi, e continua sendo, os países vizinhos, devido a facilidade gerada pela proximidade e a pela nova política de integração.

O Brasil vai aparecer como um dos maiores receptores dos imigrantes bolivianos. Como apontado por Baeninger (2012), o país se insere nessa situação a partir da atual intensificação das migrações intra-regionais, fomentadas pela permeabilidade das fronteiras sul-americanas no contexto de integração econômica regional, tornando frequente a migração do tipo transfronteiriça. Esse tipo de fluxo migratório mais recente tornou o Brasil o quarto maior estoque de imigrantes com origem em países da América Latina (BAENINGER, 2012).

Segundo os dados apresentados no Mapa 2 esses bolivianos saem de diversos municípios do país em busca de melhores condições no território brasileiro. É interessante notar que as maiores concentrações de emigrantes saem dos departamentos de La Paz e Cochabamba, região em que está a cordilheira dos Andes, e porção do país mais distante do Brasil. Outro elemento a ser destacado é o grande volume de emigrantes em municípios de baixa urbanização, ou rurais, o que pode estar relacionado ao fato, exposto aqui anteriormente, de que a população rural do país vive em condições mais precárias. Na Zona de Fronteira existe um volume menor de emigrantes para o Brasil, mas dois fatores podem estar ligados a isso: o primeiro é que a população desses municípios é menor do que a de outras regiões do país, portanto o volume de emigrantes é menor; e o segundo é que muitas vezes o indivíduo não faz migração por conta da proximidade, realizando apenas fluxos pendulares de ida e volta ao país. Em comparativo dentro da Zona de Fronteira o maior volume está no segmento sul, próximo ao Mato Grosso e Mato Grosso do Sul, mas é uma região que também pode ser utilizada como rota para São Paulo, sendo assim apenas um espaço de passagem. 


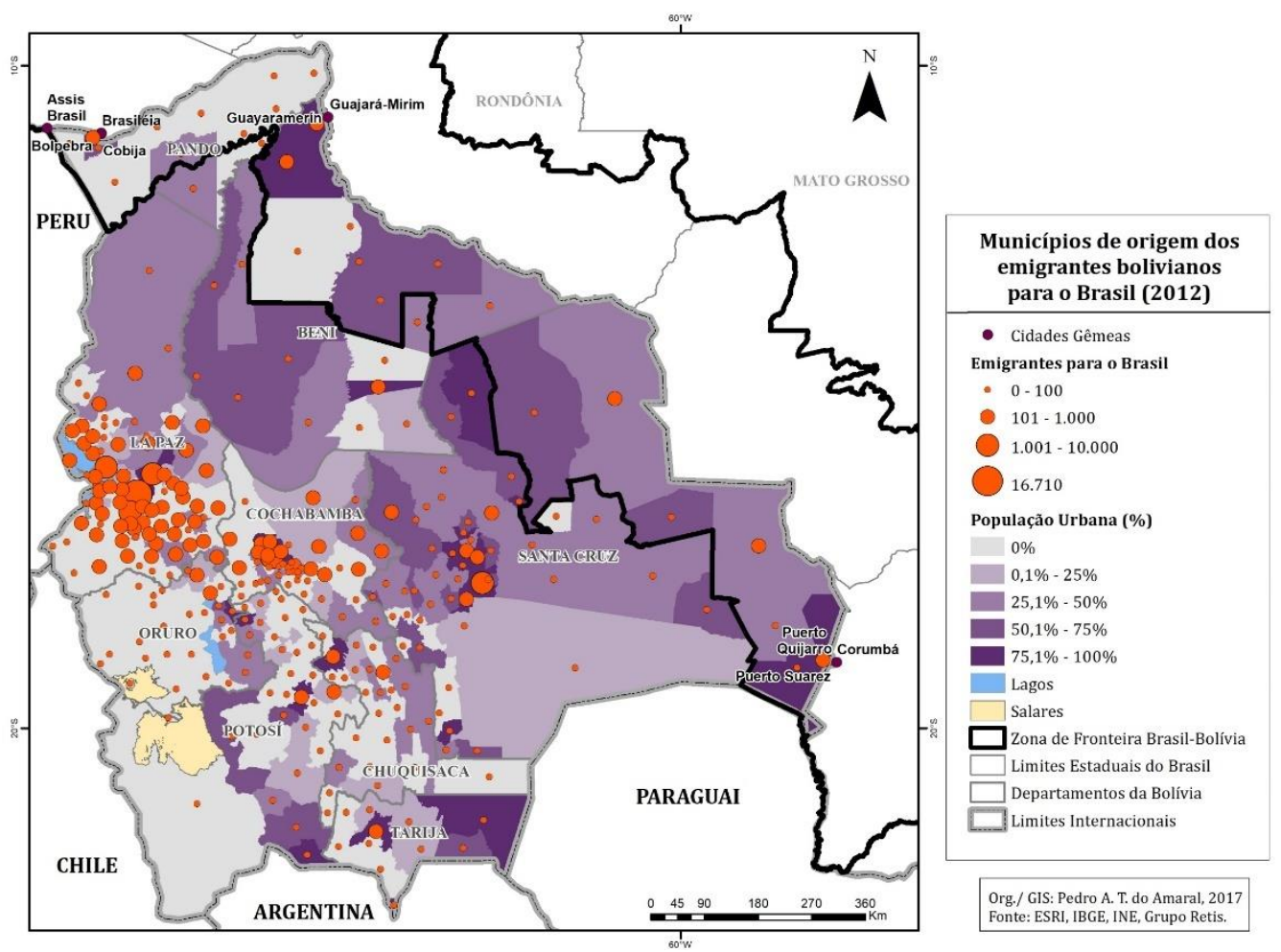

Mapa 1. Município de origem dos emigrantes bolivianos para o Brasil (2012). Org.: AMARAL, P.A.T. (2016). Fonte: Censo demográfico 2012 - INE.

Outro fenômeno que pode ser apontado é a presença de espaços mais urbanizados na Zona de Fronteira com o Brasil. A intensa troca de fluxos comerciais e a saída da população do campo em direção ao Brasil servem como atrativo para se deslocar para as cidades próximas ao lado brasileiro, gerando a formação e expansão de centros urbanos nestas localidades fronteiriças, em especial nas cidades gêmeas.

\section{A entrada de trabalhadores imigrantes bolivianos no mercado de trabalho do Brasil}

Ao mesmo tempo em que houve esse processo de integração regional ocorreram mudanças no Brasil que proporcionaram esse 'boom' migratório. Durante os anos 1990 ocorreu a consolidação econômica, depois do período de instabilidade monetária e financeira, e política, com o processo de redemocratização do final dos anos 1980. Isto acaba por colocar o Brasil com o papel de potência dentro da América do Sul, justificando assim a grande atratividade para a migração transfronteiriça (SOARES et. all., 2015). Segundo Souchaud (2010), a busca dos bolivianos pelo Brasil se intensifica justamente durante esse período de consolidação econômica e política do país.

Ao longo dos anos mais recentes essa entrada de bolivianos foi constante. Segundo os dados da Polícia Federal (gráfico 2), a entrada de pessoas de nacionalidade boliviana foi sempre presente, dos anos de 2000 a 2015, com alguns momentos de maior crescimento, como em 2005, 2008 e 2011. Comparado aos anos de registro o padrão de anos pico e de baixa se repete, porém em anos diferentes, sendo os maiores em 2006, 2009, 2012. 


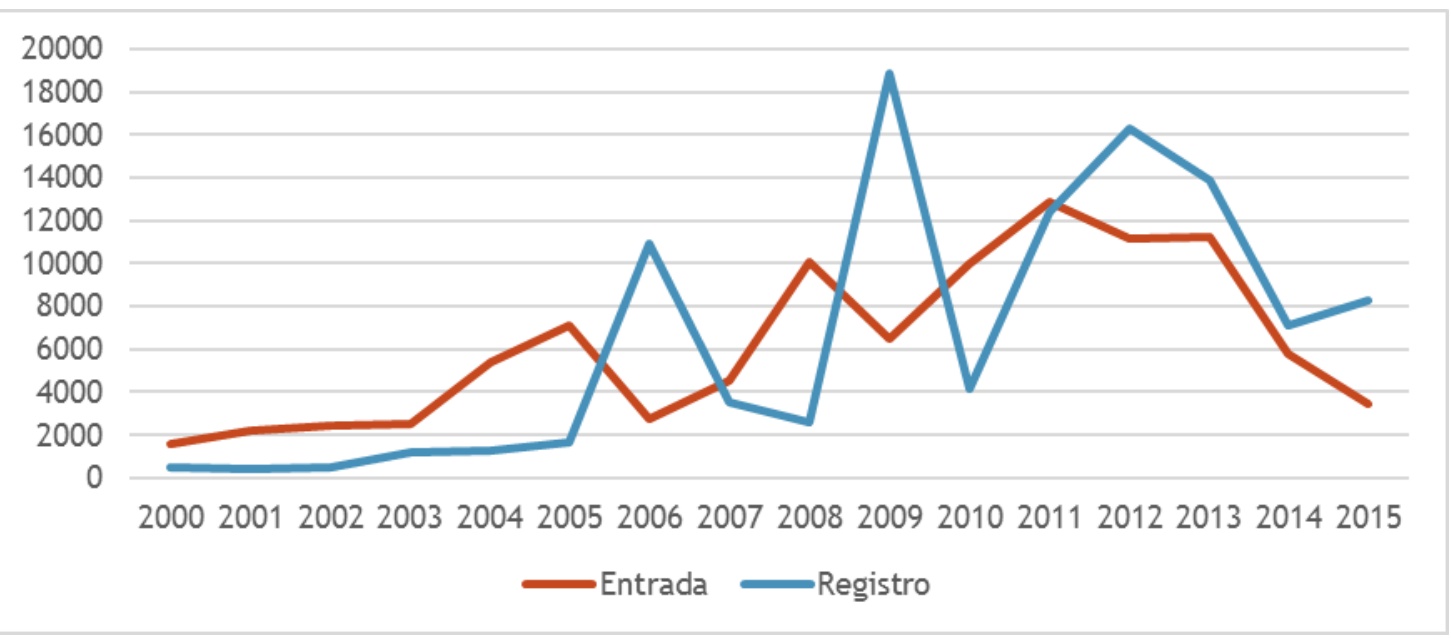

Gráfico 1. Anos de entrada e de registros de bolivianos no Brasil (2000 - 2015). Org.: AMARAL, P.A.T. (2018). Fonte: SINCRE (2000-2015).

Dois elementos chamam a atenção, o primeiro é que os anos de registro de maior alta são exatamente um ano depois dos anos de alta de entrada, o que mostra um fenômeno de demora para estabelecer o registro. O segundo é que esses anos correspondem a mudanças nas leis de migração, e a maior parte dos registros feitos nesses anos correspondem ao amparo dessas mudanças. Em 2006 muitos dos registros feitos tiveram o amparo do acordo Mercosul, aprovado por decreto do Congresso Nacional em setembro de 2005. Já em 2009, ano com o maior número de registros durante todo o período analisado, os amparos são correspondentes, na grande maioria dos casos, a Lei 11.961 que anistiou os imigrantes que haviam entrado no país de forma irregular e poderiam agora se regularizar, portanto permitiu o registro de muitos que haviam entrado em anos anteriores. Por fim, em 2012, último ano de maior alta dos registros, os amparos legais que foram dados aos imigrantes registrados foram correspondentes a entrada em vigor no plano jurídico do acordo Mercosul em 2009, abrindo mais possibilidades de registro não só para permanentes, como para os temporários também.

Analisando essa condição de migração, o que se observa, a partir do gráfico 3, é que durante os anos de 2000 a 2012 os registros de permanentes correspondiam a mais de 50\% dos registros feitos, o que mostra que a maior parte dos imigrantes bolivianos registrados migraram em definitivo. Nos últimos anos, de 2013 a 2015, esse panorama se reverte, passando a haver um maior registro de imigrantes temporários. Dois fatores podem ter influenciado para essa mudança, o primeiro seria justamente a partir da instituição do acordo Mercosul, que permitiu o maior registro de temporários, para um período de dois anos, para os países membros e signatários do acordo. O outro fator seria um desejo de maior mobilidade para esses imigrantes, querendo não se estabelecer por um longo período no Brasil. Chama a atenção também o baixo número de registros na situação de fronteiriço, mesmo sendo uma fronteira muito movimentada. Essa baixa procura pode estar ligada à um desinteresse pela situação de fronteiriço, por desejaram se deslocar também para o interior do país, ou também pela falta de conhecimento dessa legislação, já que o acordo para permanentes e temporários é amplamente divulgado. 


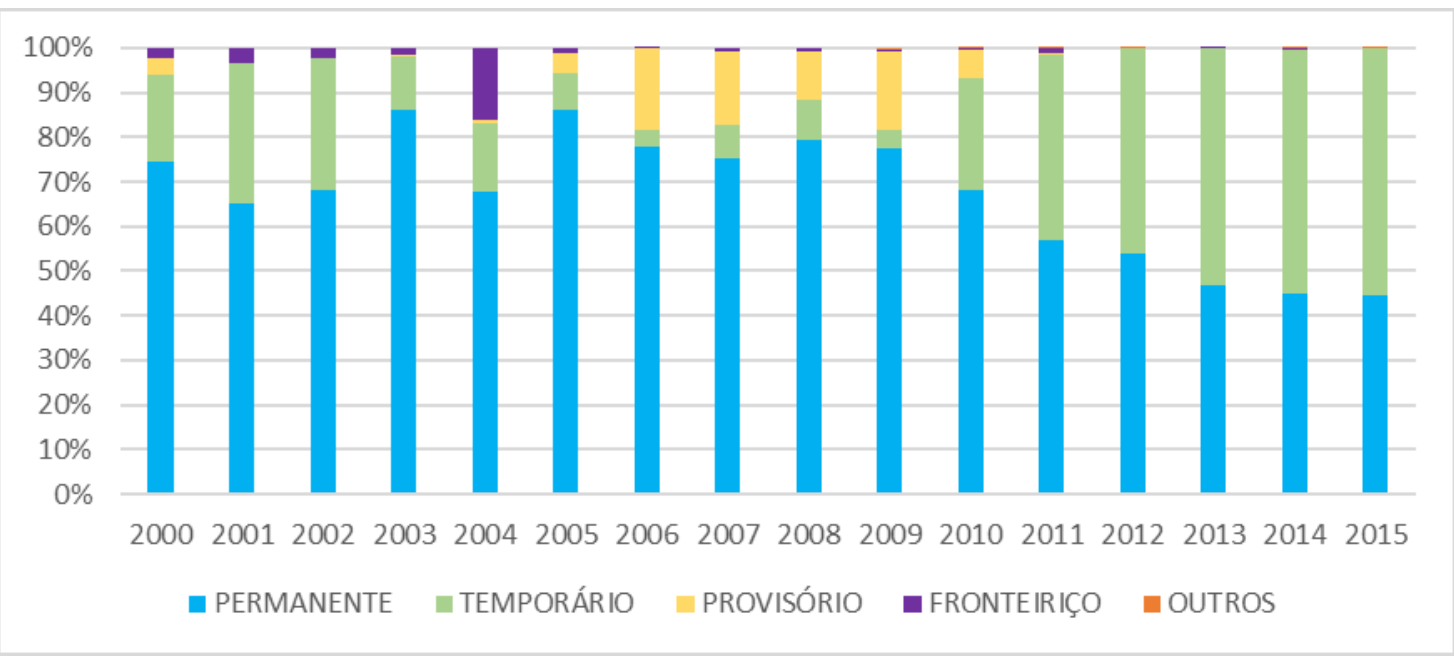

Gráfico 2. Categoria dos registros realizados pelos bolivianos no Brasil (2000 - 2015). Org.: AMARAL, P.A.T. (2018). Fonte: SINCRE (2000-2015).

Esses migrantes bolivianos, sejam eles temporários ou permanentes, se deslocam para dentro do Brasil e se estabelecem em diversas cidades. É possível observar, no mapa 3, que a entrada desses imigrantes se dá muito pelos estados da fronteira, principalmente pelo Mato Grosso do Sul, com mais de 63 mil imigrantes dentre os que foram registrados no período de 2000 a 2015. Isso mostra que muitos deles estariam entrando por vias terrestres. Porém, apesar dessa maior entrada pela fronteira as maiores concentrações de bolivianos se dão em São Paulo, principalmente na capital com quase 80 mil bolivianos registrados, mostrando como os grandes centros econômicos do país ainda são o maior atrativo para esses imigrantes. Já dentro da faixa de fronteira destacaram-se principalmente as cidades gêmeas de Guajará-Mirim e Corumbá, onde existe uma grande permanência desses imigrantes, provavelmente devido à proximidade com as cidades bolivianas. Importante destacar também que mesmo tendo um número menor de bolivianos registrados na fronteira, isso não significa que eles ocupam pouco as cidades ou o mercado de trabalho, já que muitos podem estar realizando movimentos pendulares de entrada e saída, sem serem registrados. 

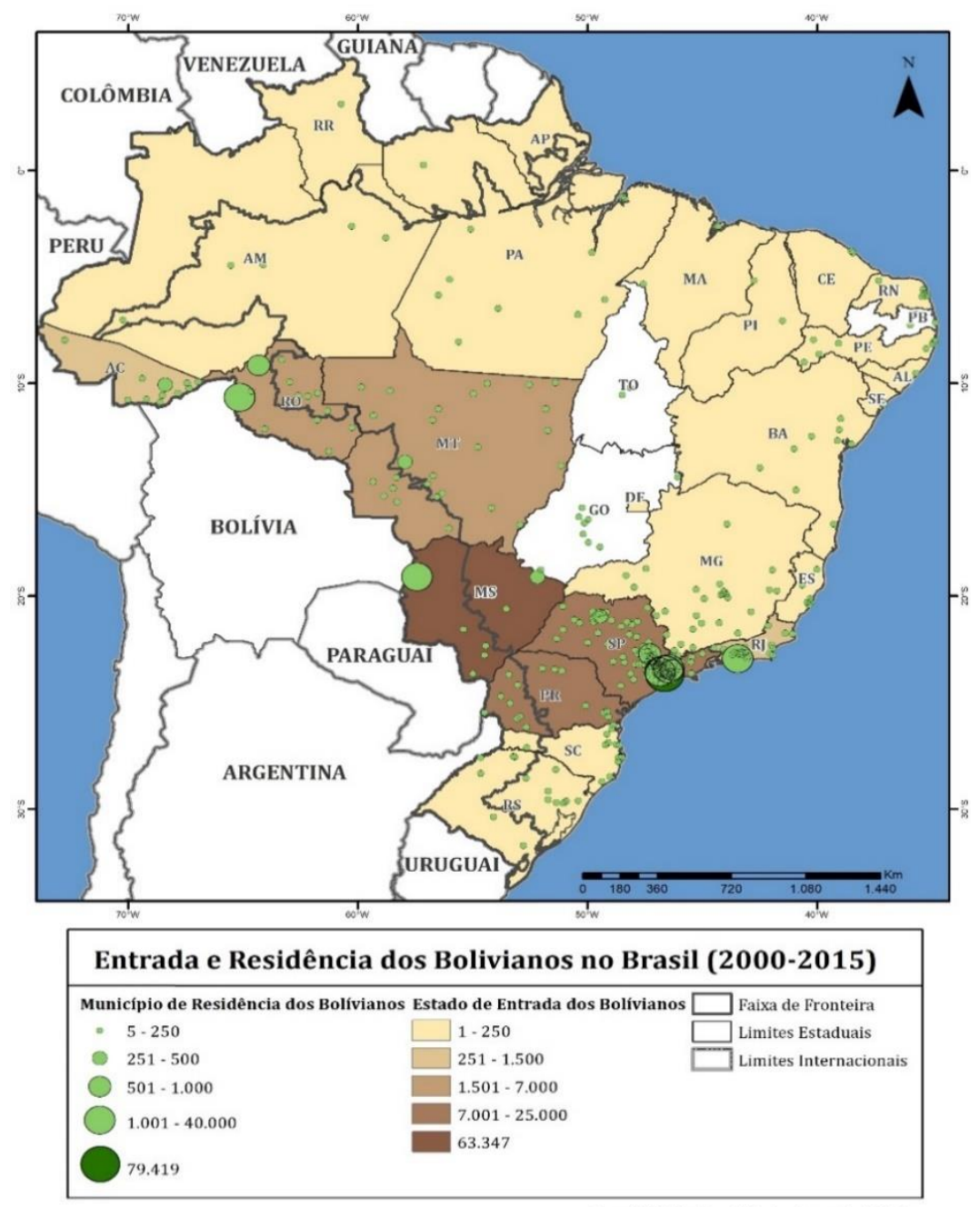

Org./ GIS: Pedro A. T. do Amaral, 2018 Fonte: ESRI, IBGE, SINCRE, Grupo Retis.

Mapa 2. Entrada e residência dos bolivianos no Brasil (2000 - 2015). Org.: AMARAL, P.A.T. (2018). Fonte: SINCRE (2000-2015).

Dentro desses municípios os bolivianos exercem diferentes atividades de trabalho quando em situação ativa. Segundo a Polícia Federal $66,4 \%$ dos bolivianos registrados estariam exercendo a atividade categorizada como decorador (gráfico 4). De acordo com o SINCRE, essa categoria corresponde a atividades como costura e alfaiataria. Segundo Freitas (2013), essas atividades ligadas a indústria têxtil estão muito presentes entre os bolivianos residentes em São Paulo, o que mostra o porquê desse alto percentual. O restante das atividades não ultrapassa os 3\%, o que vai aparecer com um percentual um pouco maior são os estudantes, ou seja, não exercendo atividades trabalhistas. 


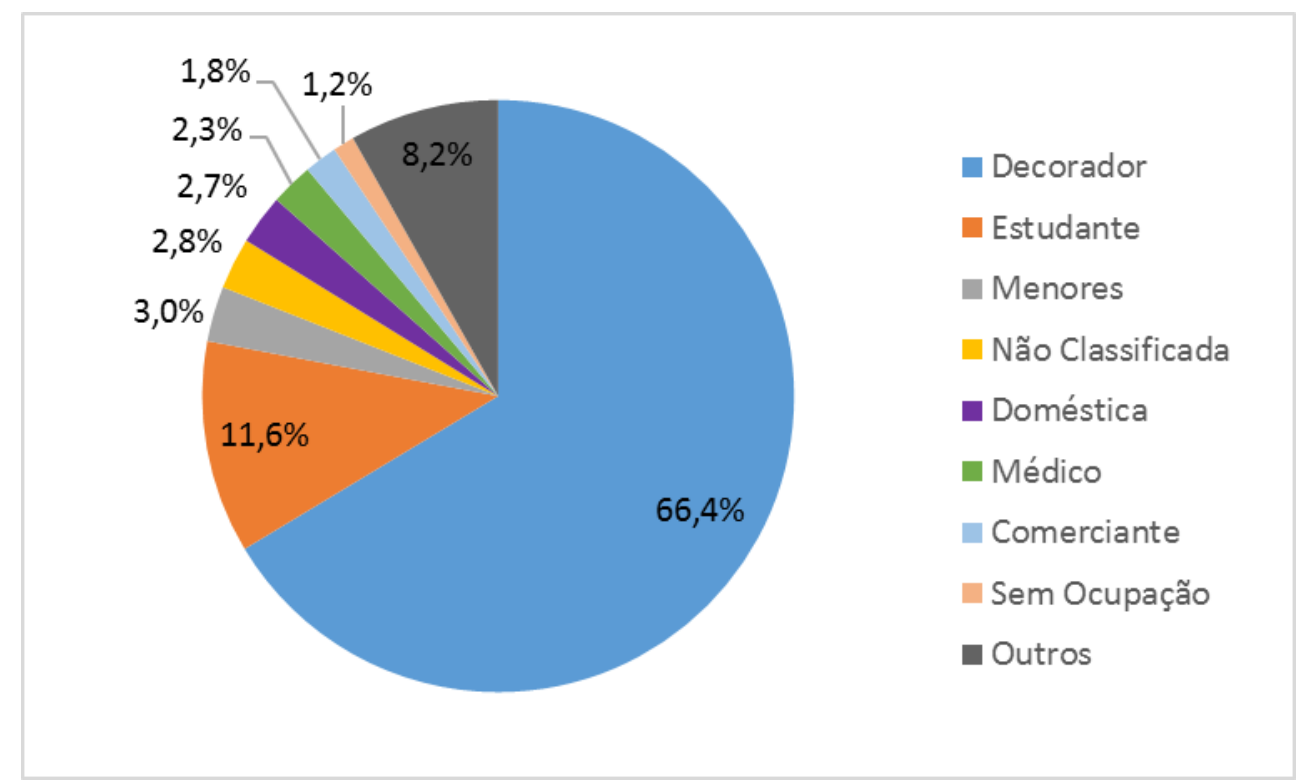

Gráfico 3. Categoria de emprego sendo exercido durante o seu registro (2000-2015). Org.: AMARAL, P.A.T. (2018). Fonte: SINCRE (2000-2015).

Em relação as atividades exercidas no mercado de trabalho formal dentro da Zona de Fronteira o que se observa é que existe um grande padrão do lado da região de fronteira da Bolívia, na qual a maioria dos municípios tem a maioria de trabalhadores em atividades agropecuárias (Mapa 3). As maiores exceções são justamente as cidades gêmeas de Cobija (Pando), Guayaramerín (Beni) e Puerto Suarez e Puerto Quijarro (Santa Cruz), provavelmente pelo fato de ser um mercado movimentado pelas trocas comerciais de ambos os lados. No lado da Faixa de Fronteira do Brasil existe uma maior diversidade, com municípios de predominância dos setores de administração pública, indústrias de transformação, agropecuária e comércio. No setor de comércio existe um forte espelhamento com relação as cidades gêmeas respectivas de Assis Brasil (AC), GuajaráMirim (RO) e Corumbá (MS). Dos bolivianos que foram exercer atividades nos municípios de fronteira é possível observar que eles exercem um trabalho bem diferente do padrão apresentado em São Paulo, já que esses corresponderam mais as atividades de comércio, agropecuária e educação. Essas atividades muitas vezes são semelhantes aos setores principais dos seus municípios de residência, mas um pouco diferente do que teria nos municípios de origem. 


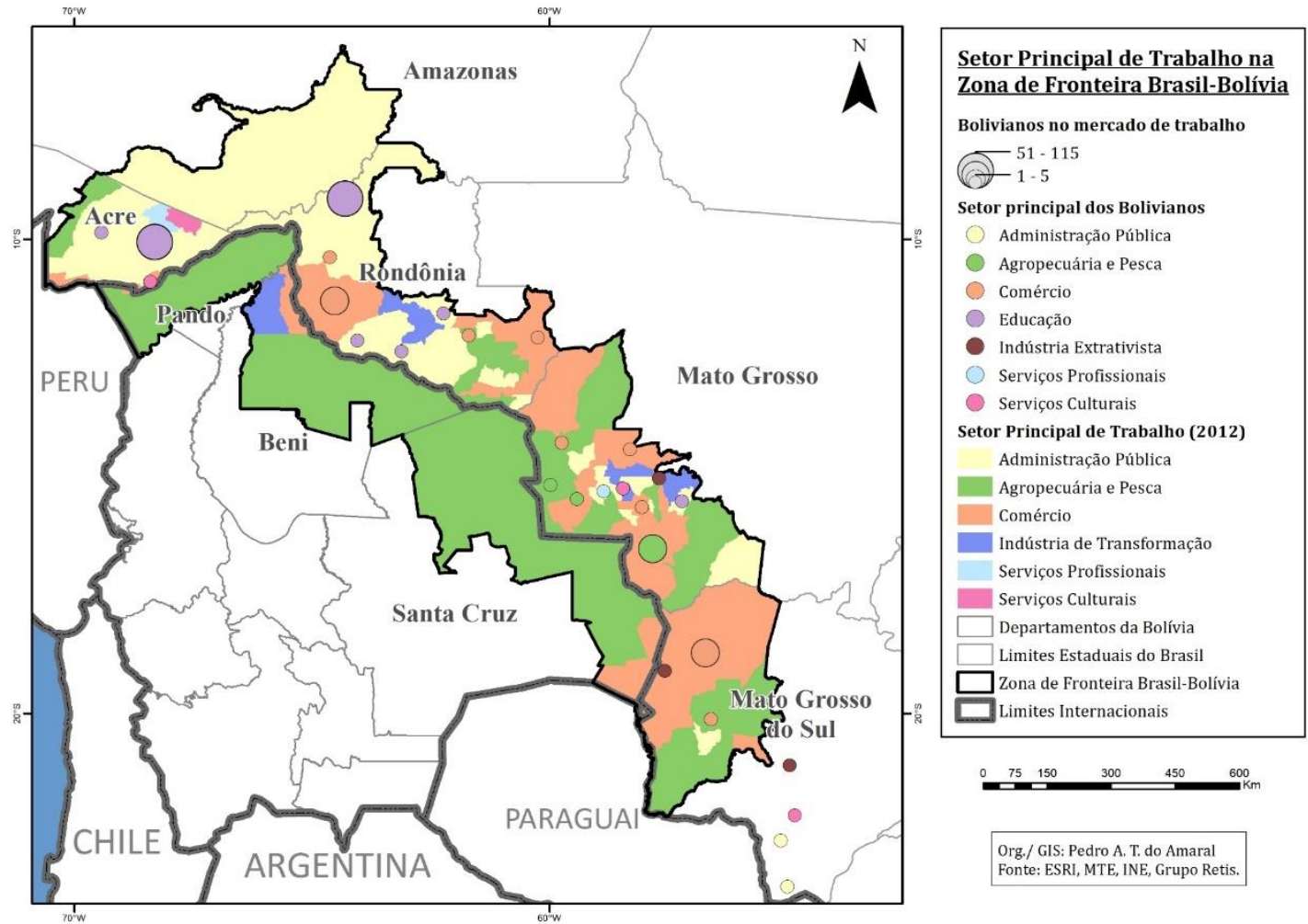

Mapa 3. Setor Principal de Trabalho na Zona de Fronteira Brasil-Bolívia. Org.: AMARAL, P.A.T. (2018). Fonte: RAIS (2002-2014) - TEM.

Um dos objetivos destes imigrantes é a busca por oportunidades de trabalho, renda e condições sociais oferecidas por um outro Estado, sendo elas melhores do que no país de origem. Por conta disso é importante a inserção do imigrante no mercado de trabalho brasileiro. Para a sua fixação e maior estabilidade há uma busca pelo mercado de trabalho formal, que poderá garantir mais diretos, estabilidade e melhor renda, como é caso dos apresentados nos resultados anteriores. Porém nem sempre esses imigrantes conseguem se inserir no mercado formal, seja pela dificuldade gerada pelas faltas de ofertas e oportunidades, mas principalmente pela falta de registro, já que os imigrantes irregulares não podem exercer atividades formais regularmente. Dentro do contexto da cidade esses trabalhadores bolivianos buscam pelas mais diversas formas de trabalho para gerar sua renda, podendo ser inclusive dentro do mercado informal. Como mostra o Quadro 1, apesar de ter aumentado consideravelmente o número de trabalhadores formais, segundo os dados do RAIS (AMARAL 2017), ainda há uma grande maioria de bolivianos imigrantes trabalhando no mercado informal, segundo o Censo Demográfico de 2010. Em quase todas as cidades em que há uma grande quantidade desses imigrantes a maioria está no mercado informal, como por exemplo em São Paulo, onde a principal concentração desses trabalhadores está (aproximadamente 85\% dos trabalhadores) no mercado informal. Isso acontece a despeito do que ocorre na cidade, pois não é em função da condição do seu mercado de trabalho. No comparativo com o total de trabalhadores das cidades a maioria delas possui um mercado de trabalho mais formal do que informal, o que mostra a condição marginalizada de grande parte desses trabalhadores. 
Quadro 1. Trabalhadores bolivianos $X$ Trabalhadores totais nas principais cidades de residência dos bolivianos ${ }^{1}$ (2010).

\begin{tabular}{|c|c|c|c|c|c|c|c|c|c|}
\hline & & \multicolumn{4}{|c|}{ Bolivianos } & \multicolumn{4}{|c|}{ Total } \\
\hline & & Formal & $(\%)$ & Informal & $(\%)$ & Formal & $(\%)$ & Informal & $(\%)$ \\
\hline Guajará-Mirim $^{2}$ & RO & 160 & $27 \%$ & 442 & $73 \%$ & 7.113 & $47 \%$ & 8.064 & $53 \%$ \\
\hline Corumbáa $^{2}$ & MS & 89 & $20 \%$ & 352 & $80 \%$ & 22.449 & $51 \%$ & 21.166 & $49 \%$ \\
\hline Porto Velho ${ }^{2}$ & RO & 142 & $35 \%$ & 267 & $65 \%$ & 122.685 & $61 \%$ & 76.812 & $39 \%$ \\
\hline Epitaciolândia ${ }^{2}$ & $\mathrm{AC}$ & 56 & $37 \%$ & 97 & $63 \%$ & 1.731 & $30 \%$ & 3.954 & $70 \%$ \\
\hline Costa Marques ${ }^{2}$ & RO & 16 & $13 \%$ & 111 & $87 \%$ & 1.581 & $29 \%$ & 3.925 & $71 \%$ \\
\hline Rio Branco $^{2}$ & $\mathrm{AC}$ & 43 & $39 \%$ & 68 & $61 \%$ & 77.519 & $56 \%$ & 59.745 & $44 \%$ \\
\hline Cáceres $^{2}$ & MT & 20 & $19 \%$ & 86 & $81 \%$ & 17.935 & $50 \%$ & 18.286 & $50 \%$ \\
\hline São Paulo & $\mathrm{SP}$ & 2.495 & $16 \%$ & 13.306 & $84 \%$ & 3.592 .581 & $65 \%$ & 1.953 .886 & $35 \%$ \\
\hline Guarulhos & SP & 48 & $3 \%$ & 1.346 & $97 \%$ & 369.704 & $65 \%$ & 197.105 & $35 \%$ \\
\hline Rio De Janeiro & RJ & 215 & $57 \%$ & 165 & $43 \%$ & 1.897 .499 & $65 \%$ & 1.022 .834 & $35 \%$ \\
\hline Carapicuíba & $\mathrm{SP}$ & 45 & $14 \%$ & 272 & $86 \%$ & 114.663 & $70 \%$ & 50.222 & $30 \%$ \\
\hline Osasco & SP & 36 & $15 \%$ & 211 & $85 \%$ & 217.982 & $69 \%$ & 99.808 & $31 \%$ \\
\hline Campo Grande & MS & 16 & $9 \%$ & 169 & $91 \%$ & 238.148 & $59 \%$ & 166.231 & $41 \%$ \\
\hline Itaquaquecetuba & $\mathrm{SP}$ & 23 & $15 \%$ & 129 & $85 \%$ & 81.255 & $61 \%$ & 52.364 & $39 \%$ \\
\hline Ribeirão Preto & SP & 145 & $100 \%$ & 0 & $0 \%$ & 212.847 & $66 \%$ & 110.982 & $34 \%$ \\
\hline Manaus & $\mathrm{AM}$ & 38 & $29 \%$ & 92 & $71 \%$ & 433.996 & $58 \%$ & 312.526 & $42 \%$ \\
\hline Americana & $\mathrm{SP}$ & 0 & $0 \%$ & 125 & $100 \%$ & 75.069 & $67 \%$ & 37.395 & $33 \%$ \\
\hline Cuiabá & MT & 92 & $91 \%$ & 9 & $9 \%$ & 170.369 & $61 \%$ & 110.495 & $39 \%$ \\
\hline
\end{tabular}

${ }^{2}$ Dentro da Faixa de Fronteira. Em negrito as cidades gêmeas

\section{Considerações Finais}

A partir do levantamento feito sobre a importância do fenômeno fronteiriço para a estrutura e dinâmica do mercado de trabalho e dos resultados dos dados analisados foi possível chegar a algumas considerações acerca dessa questão na Zona de Fronteira do Brasil com a Bolívia. O primeiro ponto considerado é que devido ao período de crise instaurada na Bolívia o mercado brasileiro se tornou atrativo, principalmente devido as políticas de aproximação dos dois países, visando uma maior integração. Esse movimento foi visto a partir da maior entrada de bolivianos no Brasil, principalmente em anos de acordos políticos que facilitaram para o registro desses imigrantes.

O segundo elemento de destaque é em relação aos locais para os quais esses imigrantes foram dentro do Brasil. Dentro da Faixa de Fronteira apareceram com maior destaque as cidades gêmeas de Corumbá (MS) e Guajará-Mirim (RO), porém os principais destinos estão fora da fronteira, mais precisamente na cidade de São Paulo e para os municípios do entorno. Essa região tem uma densidade econômica muito maior, o que faz com que o deslocamento para lá seja mais atrativo, pela busca por mais oportunidades de trabalho e renda.

Por fim, com relação as atividades exercidas pelos bolivianos no Brasil, observa-se uma concentração na indústria têxtil, muito movimentada no estado de São Paulo, onde a maioria dos imigrantes estão. Na fronteira, dentro do mercado formal as atividades de destaque foram próximas àquelas que os municípios já apresentavam, sendo a maioria no comércio, agropecuária e educação, ainda que bem diferentes dos seus locais de origem. Fora desses levantamentos ainda existe uma grande quantidade de imigrantes bolivianos trabalhando no setor informal da economia, por isso muitas vezes invisibilizados pelas bases de dados. No levantamento do Censo de 2010 eles apareceram, em sua maioria, como informais em quase todos os municípios em que estão residindo, mesmo que o município em geral não tenha um mercado informal tão grande, o 
que demostra ainda uma grande marginalização dos imigrantes bolivianos, que sofrem em muitos casos da falta de oportunidades e, em alguns casos, de xenofobia.

Aprovado pela Comissão Científica do III CONGEO - Congresso Brasileiro de Geografia Política, Geopolítica e Gestão do Território Universidade Federal Fluminense - Niterói (RJ), 2018 
Referências

AMARAL, P.A.T. Mercado de trabalho na Zona de Fronteira Brasil-Bolívia: a mobilidade de trabalhadores bolivianos para o brasil. Revista GeoPantanal, v. 12, p. 367-382, 2017.

BAENINGER, R. O Brasil na rota das migrações latino-americanas. In: Imigração Boliviana no Brasil. 1ed.Campinas, SP: NEPO-UNICAMP, 2012, v. 1, p. 9-18.

BANDEIRA, L. A. M. As políticas neoliberais e a crise na América do Sul. Revista brasileira de política internacional, v. 45, n. 2, p. 135-146, 2002.

BRASIL. Lei n.11.961, de 2 de julho de 2009. Dispõe sobre a residência provisória para o estrangeiro em situação irregular no território nacional e dá outras providências. Brasília. 2009.

Projeto de Lei do Senado $\mathbf{n}^{\circ} \mathbf{2 8 8}$, de 2013. Dispõe sobre o ingresso, permanência e saída de estrangeiros no território nacional, o instituto da naturalização, as medidas compulsórias, transforma o Conselho Nacional de Imigração em Conselho Nacional de Migração, define infrações e dá outras providências. Brasília. 2017

FREITAS, P. T. Bolivianos (as) por entre oficinas de costura na cidade de São Paulo: novos aspectos da dinâmica migratória no século 21. Coleção Por dentro do Estado de São Paulo. Campinas: Núcleo de Estudos de População, v. 9, 2013.

HOUSE, J. W. The Frontier Zone: A Conceptual Problem for Policy Makers. In: International Political Science Review. Vol. 1, págs. 456-477, 1980.

MACHADO, L. O. Limites, Fronteiras e Redes. In: STROHAECKER, T. M. et al. (org.). Fronteiras e Espaço Global. AGB - Porto Alegre, Porto Alegre, 1998, p.41-49.

MERÇON, M. Imigrantes bolivianos no trabalho escravo contemporâneo: análise do caso Zara a partir das RPGS. In: VI Jornada Internacional de Políticas Públicas, 2013, São Luis. VI Jornada Internacional de Políticas Públicas. São Luis: UFMA, 2013. p. 34-44.

SOARES, W.; LOBO, C.; MATOS R. Mobilidade espacial dos imigrantes estrangeiros no Brasil 1991/2010. REMHU - Revista Interdisciplinar Mobilidade Humana, Brasília, Ano XXIII, n. 44, p. 191-205, jan./jun. 2015.

SOUCHAUD, S. A imigração boliviana em São Paulo. Deslocamentos e reconstruções da experiência migrante, p. 267-290, 2010. 